\title{
MENGGAGAS AGAMA BARU \\ DI ERA POSTMODERNISME
}

\author{
Muhammad Zain
}

\begin{abstract}
When man has come to the highest level of achievement of the use of ratio, well known as postmodern era, religion is still believed to be the solution of humanistic problems. Even in the ultimate level of the use of ratio, religion becomes an expectation. This expectation will never be a reality unless religion can play its part in our every day life.

Religion nowadays is understood formally, partially and exclusively. This makes it hard for the religion to cope with the ongoing problems encountered by buman beings. To make thing worse, this understanding even can lead to a more severe condition where religion is blamed to be the cause of some social chaos, riots, violence, oppression and injustice.

Therefore, to make the dream comes true, religion should be able to play its role universally, as the characteristics of its values. Moreover, if it is believed that a religion comes from the Al-Mighty God, the God of all universes, the values and teachings of the religion are values that go into effects to the whole bumankind.
\end{abstract}

Keywords: Modernisme, Postmodernisme, Spiritualitas, Universalisme Agama.

TIDAK berlebihan jika dikatakan bahwa postmodernisme (selanjutnya disebut postmo) dapat diibaratkan sebagai rimba belantara. Luas, padat, rimbun, penuh tikungan yang menggoda, dan tanpa pusat. Mudah menyesatkan. Kaya flora dan fauna, dengan jutaan cahaya warna-warni, suara, energi kehidupan, misteri, dan juga kemungkinan daya. ${ }^{1}$

Kata-kata kunci yang lekat pada postmo seperti dekonstruksi, difference, diskontinuitas sejarah, discourse, dan decentering menjadi seperangkat alat deteksi apa saja. Semuanya dapat saja dikait-kaitkan dengan, dan dilihat serta dibahas melalui kacamata postmo. ${ }^{2}$ Ia menggoda tetapi juga membongkar; ia

${ }^{1}$ Ariel Heriyanto "Postmodernisme yang Mana? Tentang Kritik dan Kebingungan dalam Debat Postmodernisme di Indonesia", Kalam, Edisi 1 (1994), 80.

2Lihat Ahmad Sahal "Kemudian" dimanakah Eansipasi? Tentang Teori Kritis Genealogi dan Dekonstruksi”, Ibid., 12. 
mencerahkan, tetapi juga mencemaskan, ia merealita tapi tak (sulit) terdefinisikan. Ia datang mengkritik, mengusik kemapanan modernisme, monopolinya, dan menggeser wacananya. Wacana yang tertindas, terpinggirkan, terpedaya menjadi terberdayakan. Narasi-narasi besar diketepikan dan digantikan dengan narasi-narasi kecil. Majemuk, bergerak, tak hirarkis, tanpa perspektif, terputus-putus, tidak sistematis. Itulah realitas PM. Begitukah? Membingungkan? Salah kaprah? Salah alamat?

Tulisan ini berupaya membahas keterpautan antara gejala postmo dan bangkitnya kesadaran beragama baru. Atau lebih konkretnya, kegelisahan akademik yang melatarinya adalah bagaimana "wajah agama" di tengah gemuruh PM? Penulis berasumsi bahwa dunia postmo yang bercirikan dekonstruksi atas modernisme, seperti klaim universalisme kebenaran (rasional) digantikan dengan kebenaran yang partikularistik; superioritas Barat berhadapan dengan inferioritas Timur digantikan dengan "wacana dialog" antara keduanya, pasti berdampak pada "kebangkitan agama-agama". Dalam konteks inilah, kearifan dalam merespons tatanan baru tersebut sangat dibutuhkan, karena carutmarut gejala postmo sudah barang tentu berkait berkelindan dengan kebangkitan agama-agama.

\section{Menolak Modernisme?}

Benarkah postmo datang untuk mencukupsudahi kejayaan modernisme? Jika diasumsikan bahwa kehadiran postmo adalah untuk "menolak" modernisme, maka sulit diterima sebelum kita memetakan modernisme itu sendiri. Modernisme dapat dimaknai terutama di bidang filsafat diawali gerakan pemikiran yang diinspirasi Rene Descartes, dikokohkan oleh gerakan englightenment atau Aufklarung, dan mengaktualisasikan dirinya hingga abad XX lewat dominasi sains dan kapitalisme. Namun, janji-janji pencerahan modernisme berupa kebahagiaan total manusia, ternyata gagal, tak mewujud. Sejarah modernitas yang ditandai oleh dominasi rasio, muncul dalam baju sains yang kemudian mewujud menjadi saintisme telah menunjukkan dirinya sebagai "mitos baru". Akibatnya, saintisme dan industrialisasi berubah menjadi imperialisme, eksploitasi manusia atas manusia, superioritas Barat dan inferioritas Timur, nilai-nilai religi tergusur, terpinggirkan. Nestapa manusia modern? Mereka mengalami krisis spiritualitas? Dominasi mayoritas, tirani minoritas? Muncul pemutlakan kebenaran, universalisme kebenaran rasio, dan arogansi kekuasaan semakin menjalar. Di sinilah, kemudian muncul perlawanan terhadap modernisme 
(baca: saintisme) yang terbukti telah menjerumuskan manusia dalam berbagai krisis. Berbagai krisis itu bersumber dari pandangan modernisme yang dualistik, positivistik, materialistik, militeristik, dan bangkitnya tribalisme. ${ }^{3}$

Pandangan dualistik modernisme yang membagi seluruh kenyataan menjadi subjek-objek, spiritual-material, manusia-dunia, mengakibatkan objektivikasi alam dan mengeksploitasinya secara semena-mena yang berakibat krisis ekologi. Lebih dari itu, objektivikasi dan pandangan positivistik modernisme yang cenderung melihat manusia sebagai objek, dan masyarakat sebagai "mesin", mengakibatkan masyarakat diperlakukan "tidak manusiawi" (antibumanisme).

Ilmu-ilmu positif-empiris yang dijadikan sebagai standar kebenaran tertinggi dalam modernisme mengakibatkan nilai-nilai moral dan agama kehilangan wibawa dan akhirnya tergeser dan terpinggirkan. Nilai-nilai moral-spiritual tergantikan dengan nilai-nilai materialisme. Sehingga, realitas yang mendasari kehidupan manusia bukan lagi agama, tapi materi. Kondisi seperti di atas pada gilirannya membawa implikasi lebih jauh pada munculnya disorientasi moral-religius, yang kemudian mendorong semakin meningkatnya tindak kekerasan, keterasingan, depresi mental, dan semacamnya.

Modernisme juga melahirkan militerisme. Hal ini terjadi ketika norma agama dan moral tak berdaya bagi perilaku manusia sehingga norma objektif dan transendental telah "hilang". Kemudian yang memimpin adalah nafsu kuasa, yang dengan kekuasaannya terus menekan, dan sudah pasti mengusik ketenteraman dan kedamaian sebagai pilihan untuk mengatur manusia, meski disadari bahwa pilihan tersebut, bukan yang terbaik, kalau tidak boleh dikatakan malah terburuk, dan telah menjatuhkan manusia pada hukum rimba. Ibarat ikan di laut, meminjam istilah Mochtar Naim, yang besar dan kuat pasti "menekan" yang kecil, dan yang kecil menekan yang lebih kecil lagi. ${ }^{4}$

Dalam kondisi dunia modernisme yang penuh krisis itulah muncul gerakan-gerakan postmo untuk merevisi dan membongkar ketidakmemadaian modernisme. Dalam kerangka semacam itu perwatakan

${ }^{3}$ Lihat I. Bambang Sugiharto, Post Modernisme: Tantangan bagi Filsafat (Yogyakarta: Kanisius, 1996), 29-30.

${ }^{4}$ Mochtar Naim, "Masa Depan Budaya Lokal di Era Globalisasi”, Republika, 10 Oktober 1997. 
postmo dapat dikatakan menggantikan perwatakan modernisme. Berikut pemetaan Jo Verhaar ${ }^{5}$ :

\section{Table 1}

Kategori dan Perwatakan Purnamodernisme ala Jo Verhaar

\begin{tabular}{|c|c|}
\hline Modernisasi & Purnamodernisme \\
\hline $\begin{array}{l}\text { Menekankan pada empat unsur, yaitu: (a) } \\
\text { prioritas teori ilmu pengetahuan sebagai } \\
\text { dasar kegiatan intelektual; (b) pelambangan } \\
\text { identitas manusia sebagai "aku"/subjek- } \\
\text { tivitas; (c) Konsepsi "interioritas" yang } \\
\text { mengandung intuisi tentang ide-idenya } \\
\text { sendiri; (d) Usaha untuk menemukan } \\
\text { kepastian, serta penguasaannya untuk } \\
\text { menemukan kebenaran. }\end{array}$ & $\begin{array}{l}\text { Menolak keempat unsur tersebut, dan } \\
\text { memihak pada faham (a) bahwa teori } \\
\text { pengetahuan tidak berperan sebagai dasar } \\
\text { dan tergantung dari kerangka konseptual } \\
\text { yang sesuai; (b) bahwa identitas manusia } \\
\text { tidak jelas dan dapat diisi menurut tafsiran } \\
\text { yang dirasa berguna; (c) bahwa metafor } \\
\text { "interioritas" menyebabkan adanya pikiran } \\
\text { dualistis; dan (d) bahwa kekhawatiran } \\
\text { tentang kepastian berupa obsesi dengan } \\
\text { skeptisisme. (Kepastian kebenaran, No! } \\
\text { Skeptisisme, Yes! Pen) }\end{array}$ \\
\hline $\begin{array}{l}\text { Ironisme: menekankan perlunya } \\
\text { kesempurnaan individual dan melihat } \\
\text { tuntutan sosial tertentu sebagai tidak adil } \\
\text { terhadap keindividualan tersebut (M. } \\
\text { Foucault: Penganjur revolusi (melawan } \\
\text { "sistem") dengan kekerasan. Dalam sebuah } \\
\text { hal, sistemnyalah yang melanggar HAM } \\
\text { secara individual. } \\
\text { Liberalisme: mencita-citakan sosialitas } \\
\text { manusia dan memandang tuntutan } \\
\text { kebahagiaan individual sebagai hal yang } \\
\text { terkadang irasional. Contohnya, Habermas. } \\
\text { Baginya, "rasio" mesti terlepas dari cacat- } \\
\text { cacat modernisme, yakni rasio yang berciri } \\
\text { sosial, tidak individual tidak diharapkan } \\
\text { dapat memajukan komunikasi dalam } \\
\text { masyarakat pluralistis. Tidak ada dominasi } \\
\text { satu kelompok. Konkretnya, ironi tanpa } \\
\text { liberalisme (M. Foucault) dan liberal tanpa } \\
\text { ironisme (Habermas) }\end{array}$ & $\begin{array}{l}\text { Pertautan antara keduanya: ironisme dan } \\
\text { liberalisme mesti secara bersama-sama, } \\
\text { dalam masyarakat pluralitas ini untuk } \\
\text { mendamaikan kesempurnaan sosial (dalam } \\
\text { "liberalisme”) dan kesempurnaan individual } \\
\text { (dalam “ironi”). Dalam pespektif Rorty, } \\
\text { karya intelektual baru akan menghasilkan, } \\
\text { jika keduanya diperhatikan Eklektif? Agar } \\
\text { ada lagi cita-cita sosial "mewujudkan" } \\
\text { dalam bentuk politik yang hanya } \\
\text { mengakibatkan penderitaan manusia } \\
\text { lainnya. }\end{array}$ \\
\hline
\end{tabular}

5Jo Verhaar, "Purnamodernisme I-IV", Basis, No. 5-6 (Mei-Juni 1997), 73-5; No. 7-8 (Juli-Agustus 1997), 72-4; No. 9-10 (September-Oktober 1997), 70-2; No. 11-12 (November-Desember 1997), 67-71. 


\begin{tabular}{|c|c|}
\hline Modernisasi & Purnamodernisme \\
\hline $\begin{array}{l}\text { Humanisme: memandang manusia sebagai } \\
\text { sumber kemerdekaan, bebas untuk memilih } \\
\text { apa saja yang dikehendaki tanpa } \\
\text { keterbatasan apa-apa, atau juga disebut } \\
\text { sebagai eksistensialisme (J.P Sartre). } \\
\text { Belakangan, humanisme berganti kulit } \\
\text { (mengideologi) menjadi otoriter, } \\
\text { absolutisme konseptual dan pada sistem- } \\
\text { sistem sosial politik: republikanisme yang } \\
\text { sentralistik menolak perbedaan dengan } \\
\text { dengan pemerintah pusat. }\end{array}$ & $\begin{array}{l}\text { Antihumanisme: muncul untuk mencukup } \\
\text { sudahi kejayaan humanisme sebagai } \\
\text { ideologi, absolutisme itu, tampil membela } \\
\text { liberalisme, politik seperti pemerintah yang } \\
\text { terbatas kekuasaannya, pemilu multipartai } \\
\text { yang bebas, pemerintah yang sesuai dengan } \\
\text { hukum, pelayanan publik oleh pejabat } \\
\text { bebas pengaruh penguasa eksekutif, } \\
\text { perlunya kontrol sipil terhadap angkatan } \\
\text { bersenjata, media massa bebas sensor, } \\
\text { kebebasan beragama terjamin, kebebasan } \\
\text { mimbar dalam kampus dan seterusnya }\end{array}$ \\
\hline $\begin{array}{l}\text { Masyarakat pluralitas: masyarakat politik } \\
\text { atas dasar pemerintahan "nasional" yang } \\
\text { menjamin secara de facto dan de jure } \\
\text { kebebasan keyakinan agama falsafati, moral } \\
\text { dan politik. Tak ada "pemaksaan" apa pun. } \\
\text { Kebebasan adalah HAM tanpa kecuali. }\end{array}$ & $\begin{array}{l}\text { Bentuknya dalam sistem pemerintahan: (a) } \\
\text { liberalisme sistem pemerintahan demok- } \\
\text { ratis yang tidak mengharuskan prinsip- } \\
\text { prinsip filosofis dan teologis apa pun untuk } \\
\text { warga negaranya, kuasa pemerintah dimini- } \\
\text { malkan (minimal state, pen.); (b) republika- } \\
\text { nisme: dalam arti sosial politik, bukan } \\
\text { bentuk pemerintah republik, yakni sistem } \\
\text { demokrasi yang menghargai sentralisme } \\
\text { dan kehomogenan sebagai kesempurnaan } \\
\text { bentuk pemerintah; (c) komunitarianisme } \\
\text { sistem yang mengharuskan prinsip-prinsip } \\
\text { filosofis tertentu dianut sebagai cita-cita } \\
\text { kenegaraan yang dapat memperkecil gap } \\
\text { antara si miskin dan si kaya. Ini beda dari } \\
\text { komunisme yang absolutistis, sedang } \\
\text { komunitarianisme menganut demokratis. }\end{array}$ \\
\hline
\end{tabular}

Berbeda dengan kategorisasi Verharr yang didasarkan atas perspektif filosofis, ilmu-ilmu sosial, dan etika politik, Amin Abdullah lebih tertarik untuk melakukan identifikasi cara berfikir (modes of thought) ala postmodernisme. Menurutnya, paling tidak ada tiga struktur fundamental pemikiran postmodernisme, yakni deconstructionism (pembongkaran kemapanan teori-teori), relativism (gugatan atas absolutisme), dan pluralism (keanekaragaman). ${ }^{6}$ Untuk lebih konkretnya berikut akan dipaparkan secara sederhana ketiga fundamental structure postmodernisme tersebut.

${ }^{6}$ M. Amin Abdulloh, Falsafah Kalam di Era Postmodernisme (Yogyakarta: Pustaka Pelajar, 1997), 99-114. 
Table 2

Struktur Fundamental Pemikiran Postmodernisme ala M. Amin Abdullah

\begin{tabular}{|c|c|c|}
\hline $\begin{array}{c}\text { Struktur } \\
\text { Fundamental }\end{array}$ & Maksudnya & Keterangan \\
\hline Deconstructionism & $\begin{array}{l}\text { Mempertanyakan; mengkritik, } \\
\text { menyanggah, menolak dan } \\
\text { atau membongkar bangunan } \\
\text { teori (grand theory) mapan yang } \\
\text { telah dibangun modernisme, } \\
\text { selanjutnya merumuskan teori } \\
\text { baru yang lebih relevan dengan } \\
\text { realitas sosial, keberagamaan, } \\
\text { budaya dan kemajuan iptek }\end{array}$ & $\begin{array}{l}\text { Teori Max Weber tentang } \\
\text { hubungan positif antara etika } \\
\text { Protestan dan semangat } \\
\text { kapitalisme tidak dapat lagi } \\
\text { menerangkan realitas etik } \\
\text { Budhisme di Vietnam, Srilangka, } \\
\text { Thailand, dan Kambodja. Walau } \\
\text { Robert N. Bellah telah } \\
\text { membuktikannya lewat } \\
\text { penelitiannya pada masyarakat } \\
\text { Budhisme Jepang; ada korelasi } \\
\text { positif antara etika Budhisme } \\
\text { ekonomi dan modernisme Jepang. }\end{array}$ \\
\hline Relativism & $\begin{array}{l}\text { Kritis terhadap penjelasan } \\
\text { yang berbau objektif, absolut } \\
\text { apalagi universal. Absolutisme } \\
\text { dan universalisme, no way! }\end{array}$ & $\begin{array}{l}\text { Dalam kasus dan batasan HAM, } \\
\text { negara industri modern melihatnya } \\
\text { sebagai hal yang universal tidak } \\
\text { terkait dan terpengaruh dengan } \\
\text { sejarah, dan budaya setempat } \\
\text { cenderung mengikuti etika } \\
\text { universal Kant. Sementara negara } \\
\text { berkembang (dunia ketiga) } \\
\text { menganut HAM lokal kondisional } \\
\text { sangat terkait dengan sejarah dan } \\
\text { tempat mengikuti historisisme } \\
\text { Hegel. Bukankah semuanya relatif? }\end{array}$ \\
\hline Pluralism & $\begin{array}{l}\text { Sangat sulit untuk } \\
\text { mempertahankan "paradigma } \\
\text { tunggal" dalam dikursus apa } \\
\text { pun. Yang ada malah } \\
\text { keanekaan. Semuanya perlu } \\
\text { didekati dengan multidimentional } \\
\text { approaches }\end{array}$ & $\begin{array}{l}\text { Adanya kesadaran akan pluralisme } \\
\text { justru sebagai "medium" dialog } \\
\text { antaragama, budaya peradaban, } \\
\text { bukan "the clash of civilization" }\end{array}$ \\
\hline
\end{tabular}

Baik kategorisasi postmodernisme Verhaar maupun struktur fundamental pemikiran postmodernisme sangat penting artinya dalam memahami secara tepat dunia warna-warni anatomi postmo. Paling kurang akan menghindarkan untuk tidak terjebak, dan mungkin saja salah kaprah dalam menilai postmo. Antara modernisme dan postmo memang terdapat 
diferensiasi. Namun, ternyata tidak semua yang berbeda dengan modernisme adalah postmo, dan tidak semua unsur modernisme "ditolak" oleh postmo. Pada tabel berikut dapat dilihat bagaimana diferensiasi ${ }^{7}$ antara modernisme dan postmo:

Tabel 3

Diferensiasi Modernisme dan Postmodernisme

\begin{tabular}{|l|l|}
\hline \multicolumn{1}{|c|}{ Modernisme } & \multicolumn{1}{|c|}{ Postmodernisme } \\
\hline Sentralisasi & Desentralisasi \\
Pertarungan Kelas & Pertarungan Etnis \\
Konstruksi & Dekonstruksi \\
Kultur & Subkultur \\
Hermeneutis & Nihilisme \\
Budaya Tinggi & Budaya Rendah \\
Hirarkhi & Anarkhi \\
Industri & Pascaindustri \\
Teori & Paradigma \\
Kekuatan Negara & Kekuatan Bersama \\
Agama & Sekte-sekte \\
Legitimasi & Delegitimasi \\
Konsensus & Dekonsensus \\
Budaya Tradisional & Liberalisme \\
Kontinuitas & Diskontinuitas \\
\hline
\end{tabular}

\section{Gejala Postmo dan Keberagamaan Baru}

Menjelang berakhirnya abad XX dapat disaksikan perubahan yang begitu pesat, cepat, kompleks, dan terkadang paradoksal. ${ }^{8}$ Mencemaskan? Ya.

${ }^{7}$ Lihat Ibrahim M. Abu Rabi, "Beyond the Postmodernism", The American Journal of Islamic Sosial Sciences, Nomor 2, Vol. VII (1990), 254; Ihab Hassan, The Postmodernism Turns: Essays in Postmodern Theory and Culture (Columbus: Ohio University Press, 1987), 91.

${ }^{8}$ Di antara bukti paradoksal tersebut adalah ketidakbenaran ramalan John Naisbitt yang menyebut delapan megatrend Asia yang mengubah tatanan dunia, yakni: (a) perubahan dari sistem negara-bangsa menjadi sistem jaringan; (b) perubahan pandangan tentang nilai ekonomi berdasarkan pada ekspor berubah pada tuntutan pola pasar; (c) kecenderungan berpikir "menoleh" ke Timur mulai menjadi trend; (d) kontrol pemerintah digeser oleh tuntutan pasar; (e) sistem komunal pedesaan menjadi tatanan perkotaan; (f) perubahan dari sistem ekonomi pada karya menuju pada penggunaan teknologi tinggi; (g) sistem gender dominasi kaum pria akan diganti dengan kesetaraan gender; dan (h) pergeseran pusat budaya dan peredaran dari barat ke Timur. Lihat J. Naisbitt, Megatrends Asia: The Eight Asian Megatrends that are Changing the World (London: Nicholas Breakley, 1997). Namun 
Kecemasan itu tidak hanya karena bencana ekonomi, tapi juga mengakibatkan kekisruhan politik, kegagalan kehidupan sosial-budaya, dan terlantarnya tatanan nilai-moral yang ditawarkan agama. Dunia menjadi serba virtual (semu), bahkan tak ada lagi kategori-kategori moral yang mengikatnya, tatkala tak ada lagi ukuran-ukuran nilai yang membatasinya. ${ }^{9}$

John Naisbitt dan Patricia Aburdene dalam Megatrends 2000-nya memprediksi milenium ketiga sebagai abad kebangkitan agama. Keduanya menyebut sebagai New Age (era baru?) dengan slogan: Spirituality Yes, and Organized Religion No!. Keduanya banyak mengungkapkan data-data konkret mengenai kecenderungan manusia Barat yang "tiba-tiba" saja begitu haus dengan spiritualitas Timur. Mereka (penganut New Age) agak "tak peduli" dengan agama formal (Kristen dan Yahudi-Islam juga?) yang selama ini dianutnya. Kungkungan dan pengurungan agama formal dirasa tak sesuai lagi, tak mencerahkan lagi. ${ }^{10}$

Pertanyaan selanjutnya, agama yang mana yang bangkit? Apanya yang bangkit? ${ }^{11}$ Era baru agama baru? Roy Wallis—sebagaimana dikutip

pada kenyataannya yang terjadi justru sebaliknya. Hampir seluruh negara Asia mengalami krisis ekonomi berkepanjangan. Fundamental ekonominya ambruk, terpuruk. Dapat disimpulkan bahwa ternyata paradigma berpikir matematis-kalkulatif tidak dapat lagi diandalkan sebagai satu-satunya paradigma. Lihat Musa Asy'ari, "Memaknai Suatu Krisis Membangun Paradigma Pemikiran Imajinatif," Makalah dalam Pidato Ilmiah pada Senat Terbuka Dies Natalis ke-47 IAIN Sunan Kalijaga Yogyakarta, 26 September 1998, 1 dan 12.

${ }^{9}$ Lihat Yusraf Amir Piliang, Sebuah Dunia yang Terlipat: Realitas Kebudayaan Menjelang Milenium Ketiga dan Matinya Postmodernisme ( Bandung: Mizan, 1998), 72-3.

${ }^{10}$ John Naisibitt dan Patricia Aburdene, Megatrends 2000: Sepuluh Arah Baru untuk Tabun 1990-an, ter. FX Budijanto (Jakarta: Bina Aksara, 1990), 254-80. Lihat juga William Melnner, "Agama di Abad Dua Puluh Satu”, ter. Dewi Yaminah, Ulumul Qur'an, No. 5, Vol. II (1990).

${ }^{11}$ Menarik untuk menyimak analisis Ignas Kleden yang menyebut kebangkitan agama dalam tiga dimensi, yakni (a) dimensi sakralitas, yakni hubungan penganut agama dengan Yang Maha Kudus; (b) dimensi spiritualitas sikap setiap penganut agama terhadap dirinya sendiri berdasarkan nilai-nilai dan norma yang diajarkan agamanya. Ini penting untuk mencapai kesempurnaan diri; dan (c) dimensi moralitas, yakni tanggung jawab setiap penganut agama untuk mewujudkan "keselamatan" dan atau kebaikan. Titik temu agamaagama adalah dalam dimensi moralitas. Oleh karena itu, pada dataran ini, semua agama bukan hanya diharapkan dapat berdialog, tetapi lebih dari itu mesti melakukan "kerja sama" untuk mewujudkan "keselamatan". Sakralitas dan dimensi spiritualitas agama-agama tetap saja ada perbedaan dan sulit "disatukan". Lihat Ignas Kleden, "Kebangkitan Agama dalam Tiga Dimensi”, KOMPAS, 3 April 1995, 5. 
Azyumardi Azra12—memberi tipologi "new religions" (agama baru) dalam tiga kategori, yakni: agama yang menolak dunia (the world rejecting new religion); yang menegaskan dunia (the world affirming new religion); dan yang mengakomodasi dunia (the world accommodating new religion).

Mengapa timbul "agama baru"? Di antara penyebabnya adalah; (a) gagalnya sains dan teknologi dalam memberikan jawaban yang pas tentang makna (meanings) hidup. Kondisi ini diperparah lagi ketika sains-masih "netral" tidak berbalik; objektif; mewujud menjadi saintisme-mengideologi; sarat dengan interest, kepentingan-kepentingan dan juga gagal menepati janji pencerahannya berupa kebahagiaan total kepada manusia;13 (b) agama-agama besar (formal) tidak mampu lagi mengekspresikan kebutuhan-kebutuhan manusia dan kemanusiaan, agama tidak lebih sebagai sekedar masalah hubungan individual dengan Tuhan (privatisasi agama). Agama tidak tampil sebagai "suatu kebutuhan" (public religion); kebutuhan bersama; (c) dalam perspektif postmo memang ada kecenderungan untuk merombak tatanan keberagamaan "yang seragam", klaim universalisme agama mulai digugat dan diganti dengan "keterbelahan" subjek; kebenaran pihak lain sudah mulai "mengemuka". Dalam konteks ini, kecenderungan tersebut adalah sesuatu yang "alami”, dan dengan sendirinya tidak perlu dirisaukan.

${ }^{12}$ Tipe pertama, gerakan "new religions" yang menolak dunia memandang tatanan sosial yang berlaku telah menyimpang dari rencana dan ketentuan Tuhan. Sentuhan spiritualitas Tuhan telah hilang dari kehidupan manusia, sehingga mereka tenggelam dalam keculasan, frustasi, konflik, kerakusan. Tipe ini, tidak mengejar kepentingan individu melainkan mengabdi kepada seseorang "guru spiritual" (sebagai juru selamat). Termasuk dalam kategori ini The Children of God, The People's Temple, dan The Unification Church. Tipe kedua tidak memiliki panduan ritual kolektif dan teologi yang mapan. Persoalan spiritual hanya masalah individual. Sumber berbagai penderitaan dan kenestapaan terletak pada individu-individu ketimbang struktur sosial. Struktur sosial dapat berubah dan diperbaiki oleh individu-individu. Termasuk dalam tipe ini adalah Trancedental Meditation (TM) dan Nichern Shosu of American (Soka Ghokkai). Tipe ketiga, terlebih merupakan gerakan protes terhadap lembaga-lembaga keagamaan yang mapan yang kehilangan vitalitas spiritualitas yang dipandangnya sebagai inti dan substansi keberagaman. Gerakan-gerakan ini cenderung merekrut anggota dari kalangan penganut agama tradisi (mapan). Termasuk dalam kelompok ini New-Pantecostalism dan SUBUD (Susila Budhi Dharma). Lihat Azyurmadi Azra, "Kultus", dalam Rekonstruksi dan Renungan Religius Islam, ed. Muhammad Wahyuni Nafis (Jakarta: Paramadina, 1996), 20-30.

${ }^{13} \mathrm{~F}$. Budihardiman, "Ilmu-ilmu Sosial dalam Diskursus Modernisme dan Posmodernisme”, Ulumul Qur'an, Nomor 1, Vol. V, (1994), 1-4. 
Tak terbantahkan bahwa gerakan formulasi dan modifikasi "agama baru" adalah sesuatu yang "menggejala" dan/atau mengglobal. Hal itu tidak hanya terjadi di negara-negara Barat yang notabene "pencipta" sains dan sering diklaim sebagai masyarakat pascaindustrial yang mengalami "kehampaan" spiritual. Namun hal sama juga terjadi di negara berkembang sebagai bangsa "penikmat"-dalam batas-batas tertentu "korban"-sains dan budaya barat. Kasus "Haur Koneng" Tasikmalaya; dan merebaknya aliran kebatinan yang belakangan melebur menjadi "Kepercayaan Kepada Tuhan Yang Maha Esa"; 14 maraknya pendirian kelompok-kelompok meditasi, terapi spiritual dan pengobatan, ${ }^{15}$ misalnya kasus $\mathrm{Hj}$. Lia Aminuddin yang mengaku telah mendapatkan wahyu dari Allah lewat malaikat Jibril, mengaku bahwa Imam Mahdi, Mariam dan Jibril "menyatu" dalam dirinya sekaligua menobatkan putranya sebagai Nabi Isa. ${ }^{16}$

Fenomena tersebut menunjukkan bahwa, di era global ini agama bukan lagi sekedar persoalan pribadi (private), tapi justru merupakan persoalan publik. Oleh karenanya, agama adalah sesuatu yang seharusnya dideprivatisasi (deprivatized). Dalam konteks inilah, agama tetap memainkan peranan penting di era global. Agama tidak berada di pinggiran apalagi tercerabut dari konteks sosial-budaya, ekonomi, dan politik. Dengan sendirinya kondisi demikian berarti bahwa kebenaran nilai yang dikandung

${ }^{14}$ Azra, "Kultus"..., 29-30; Azyumardi Azra, "Sempalan Kok Punya Pengikut?", Amanah, No. 01, Th. X (Desember, 1995), 36.

${ }^{15}$ Untuk menyebut beberapa contoh, (a) Padepokan Anand Ashram pimpinan Anand Khrisna di Sunter Mas Barat 11 Jakarta Utara; (b) Padepokan Bhrahmana Kumaris World Spiritual University (BKWSU) pimpinan Helen Quirin (Kebangsaan Australia). Menurut Yudi Latif, di balik praktik-praktik pengobatan spiritualitas itu ada tujuan-tujuan komersialisasi dan "kekerasaan" spiritual, tidak murni sebagai "terapi" spiritual an sich. Lebih lanjut lihat Yudi Latif dan Idy Subandy, "Kekerasan Spiritual dalam Masyarakat Pasca-modern”, Ulumul Quran, No. 3, Vol. V (1994), 72-83.

16Pengalaman spiritualnya dituangkan dalam sebuah buku yang berjudul Perkenankan Aku Menjelaskan sebuah Takdir setebal 232 halaman. Fenomena Lia Aminuddin segera mengundang kontroversi. Bagi KH. Ali Yafie (Ketua MUI RI) dan M. Quraish Shihab, ia telah sesat dan menyesatkan mungkin juga sakit jiwa (kesetanan?). Di mata Shihab, ia sebetulnya sedang mengemas kebatilan dalam kebenaran. Berbeda dengan keduanya, Komaruddin Hidayat melihatnya sebagai sebuah penemuan hidup. Karena "drama eskatologis" yang selalu "laris" di pasaran agama (market of religion) yang ditawarkan sektesekte keagamaan bisa saja sebagai "pelarian" untuk menemukan dunia baru atau 'kesadaran”. Mencermati latar belakang kehidupannya yang normal menyebabkan Hidayat melihatnya sebagai penemuan makna kehidupan baru. Lihat laporan majalah Gatra, No. 42, Th. IV, 5 September 1998, 24-33. 
oleh sebuah agama bukan lagi atas nama pribadi (private), tetapi lebih merupakan hak masyarakat (public religion). ${ }^{17}$

\section{Catatan Akhir}

Dengan mempertimbangkan cara berpikir (modes of thought) dan dunia warna-warni postmo sebagai dikemukakan pada awal tulisan ini, nampaknya geliat kebangkitan agama sekaligus mempersyaratkan adanya perwajahan baru pada agama. Yang "laku" di pasar global hanyalah agama yang "mencerahkan", tidak mengurangi; apalagi "memasung". Agama yang inklusif; tidak fanatik, "lapang'22 dan tetap mempertimbangakan nilai-nilai spiritualitas lokal; dan humanistis, ${ }^{23}$ sehingga harus mengutamakan nilai-nilai kemanusiaan, keadilan, kejujuran, dan rendah hati sebagai nilai yang utama. Klaim universalisme agama formal-dalam batas-batas tertentu-dengan sendirinya sulit dipertahankan. Agama-agama formal yang mengklaim sebagai satu-satunya "pemilik" nilai universal ternyata tidak lebih sebagai "mitos baru" atau "hantu" bagi agama.

Oleh karena itu, kebangkitan agama mempersyaratkan kemauan agama untuk selalu melakukan dialog. Mengapa dialog? Sebab struktur fundamental dan/atau alur berpikir postmo, yakni pluralisme (sadar akan "yang lain") sangat mendukung tugas kemanusiaan tersebut. Lagi pula, dengan dialog justru kedua belah pihak saling menguntungkan, bukannya lewat "benturan peradaban". ${ }^{26}$

${ }^{17}$ Bachtiar Effendy, "Masyarakat Agama dan Tantangan Globalisasi: Mempertimbangkan Konsep Deprivatisasi Agama”, Ulumul Qur'an, No. 3, Vol. VII (1997), 44-8.

${ }^{22}$ Lihat Nurcholish Madjid, Pintu-pintu Menuju Tuban (Jakarta: Paramadina, 1995).

${ }^{23}$ Lihat Komaruddin Hidayat dan Muhammad Wahyuni Nafis, Agama Masa Depan Persektif Filsafat Perennial (Jakarta: Paramadina, 1995), 116-8. Konkretnya, agama masa depan adalah (a) agama yang memperjuangkan prinsip-prinsip antropik-spritualisme. Suatu kesadaran spritual yang ditopang oleh ilmu pengetahuan alam agar bisa memberikan peta kosmologi yang benar sehingga seseorang akan tahu di mana dan ke arah mana kereta ruang dan waktu yang sedang ditumpanginya; (b) agama masa depan ingin tidak terpisah dari agama-agama tradisional, bahwa juga (c) akan muncul keberagamaan eklektik dan sikap keberagamaan yang lebih humanistik-universal.

${ }^{26}$ Abdullah, Falsafah..., 111. Dalam kaitan dialog antaragamadan budaya-dalam batasbatas tertentu-untuk era sekarang adalah "passing over" (melintasi wilayah sakralitas dan spritualitas agama-agama) meminjam istilah Ignas Kleden merupakan tawaran "terbaik". Passing Over merupakan pengembaraan spiritual ke dalam agama lain, kemudian "kembali" dari tempat pengembaraan itu kepada agama semula dengan membawa pandangan baru. 
Pemahaman agama yang dialogis semacam itu merupakan sebuah keniscayaan dalam rangka meneguhkan peran agama sebagai perekat sosial (umat) dan terapi kemanusiaan. Sebab, ternyata nilai-nilai moral yang dibutuhkan, seperti kejujuran, keterbukaan, kerja keras, kesederhanaan yang diperlukan dalam kancah globalisasi ekonomi dan informasi dewasa ini merupakan konsep yang juga berakar dari agama. ${ }^{29}$ Pemahaman dialogis tentu saja menuntut adanya perubahan strategi, misi, dan dakwah yang juga lebih dialogis, ramah dan inklusif, dapat menyentuh persoalan-persoalan kerohanian dan spritualitas, bukan mengedepankan simbolisme agama. ${ }^{30}$

Agama semacam itulah yang diyakini oleh Gay Hendricks dan Kate Goodeman ${ }^{18}$ akan berkembang pada masa depan:

"Pada pasar global nanti, Anda akan menemukan orang-orang suci, mistikus, atau sufi di perusahaan-perusahaan besar atau organisasi-organisasi modern, bukan di wihara, kuil, biara, gereja atau mesjid. Manajer modern akan kembali kepada agama, tetapi tidak kepada doktrinnya yang kering, mereka merujuk pada nilai-nilai agama yang universal, seperti kejujuran, persahabatan yang tulus, cinta kasih kepada sesama manusia, sikap rendah hati, dan hidup penuh makna."

Wa al-Lâh a lam.

Jadi, pengayaan spritual. Tentu saja, bagi yang ingin melakukannya perlu "dibekali" pengetahuan yang mendalam tentang agamanya sendiri dan agama-agama yang akan "dilintasinya". Keterangan lebih memadai lihat Komaruddin Hidayat dan Ahmad Gaus AF (eds.), Passing Over Melintasi Batas Agama (Jakarta: Paramadina dan Gramedia Pustaka Utama,1998).

${ }^{29} \mathrm{Ibid}$., 352.

${ }^{30}$ Abdullah, Falsafah..., 112.

${ }^{18}$ Gay Hendricks and Kate Goodeman, The Coorporate Mystics (New York: Bantam Books, 1996) sebagai yang dilaporkan Harian Republika, 1 Desember 1998, 11. 